$\begin{aligned} & \text { Military Technical College } \\ & \text { Kobry Elkobbah, } \\ & \text { Cairo, Egypt }\end{aligned}$
ICEENG 99
on Electrical Engineering

\title{
AN IMPROVED FORMULATION FOR OPTIMAL OVERCURRENT RELAY COORDINATION USING LINEAR PROGRAMMING TECHNIQUE
}

\author{
Ammar A.Hajjar ${ }^{1}$ A.Y.Abdelaziz ${ }^{2}$ H.E.A.Talaat ${ }^{3}$ A.I.Nosseir ${ }^{4}$
}

\begin{abstract}
In this paper the problem of directional overcurrent relays coordination in interconnected power networks is presented and solved using the optimization theory. Linear programming with Simplex two-phase method is applied to minimize the operating time of the relays. The insignificance of weighting factors and far-end fault consideration in the problem formulation is proved, through a mathematical example, by simulation, mathematically, graphically and by sensitivity analysis. The current transformer (CT) selection is achieved based on the maximum load and fault currents in order to prevent the miscoordination problem resulting from CT's saturation. A complete algorithm for calculating the optimal operating times is introduced and applied to sample examples.
\end{abstract}

\section{KEYWORDS}

interconnected networks, overcurrent relay, coordination, optimization, and enhanced formulation.

1 Graduate student, Faculty of Mechanical and Electrical Engineering, Tishreen University, Latakia, Syria 2 Assistant professor, Electrical power \& Machines Department, Faculty of Engineering, Ain Shams University, Cairo, Egypt 3 Associate professor, Electircal power \& Machines Department, Faculty of Engineering, Ain Shams University, Cairo, Egypt 4 Professor, Electrical power \& Machines Department, Faculty of Engineering, Ain Shams University, Cairo, Egypt 


\section{INTRODUCTION}

Directional overcurrent relaying, which is simple and economic, is commonly used in power system protection, as a primary protection in distribution and subtransmission systems and as a secondary protection in transmission systems. The main problem that arises with this type of protection, is the difficulty in performing the relays coordination, especially in the multiloop, multisource networks [1]. Since the sixties, a great effort has been devoted for solving this problem by computer. The methods, which are used, for performing this task (relay settings) can be classified into three classes: trial and error method [2], topological analysis method [3,4], and optimization method [5-8]. Traditionally, a trial and error method is applied for relay settings. To make the coordination process faster, Knable [9] innovate the, so-called, break points which represent the relays from which the coordination process will start. The authors of $[3,4]$ have employed topological analysis method (using linear graph theory and functional dependency) for determining the optimal break points. The topological method is the best alternative, but there is no guarantee that it produces optimal relay settings.

In the optimization method, some researchers used nonlinear programming for determining the optimal settings of the pickup current and a linear programming for optmizing the time dial settings of the relays subject to the coordination constraints, and the limits of the relay settings $[5,6]$. Other researchers [7] applied the linear programming technique only to minimize operating time while the pickup currents are selected based on experience.

Urdenta et al, [5] assumed a middle-line fault in the problem formulation, to reduce the problem dimensionality. The authors of [6] used two constraints for each relay, one for close-in fault and one for far-end fault, and the objective function was considered as the sum of two additive values; the first one is the weighted sum of the operating times of the primary relays for close-in fault, and the second one is the weighted sum of the operating times of the primary relays for far-end fault. In [7], to quote: "the objective function is a weighted sum of operating times of the primary relays for close-in faults, and since the lines are short and approximately of equal length, equal weights $(=1)$ were assigned for the operating times of all the relays". Also, the authors of [8] suggested four constraints for each relay two just as in [6], and two for transient topology changes. In so doing, the problem size based on these formulations increased, which is originally large.

In this paper, the authors suggest a modified formulation to make the coordination process faster, through applying a linear programming technique, and problem dimensionality reduction. In reality, nonlinear programming is a time consuming technique, because for each iteration of the nonlinear programming another linear programming is called for determining the direction search. On the other hand, the main problem is not to determine the optimal pickup settings, but optimal time dial settings. The objective function is stated as a sum of the operating times of all primary relays for maximum close-in faults, and the constraints considered are based on the maximum close-in faults as well. So, the problem dimensionality is reduced to a half and consequently, a faster algorithm, which is more suitable for on line application is obtained. 


\section{OPTIMAL COORDINATION OF DIRECTIONAL OVERCURRENT RELAYS}

\subsection{Overview}

The directional overcurrent relay has two units, an instantaneous unit (time independent), and an inverse overcurrent unit (time dependent). The time dependent unit has two values to be set, the pickup current value (lpu,) and the time dial setting (TDS), which can be set either according to break point approach $[3,4]$ or according to the concept of optimization theory (linear programming) just as in this paper. The pickup value is the minimum current value for which the relay operates. The time dial setting defines the operating time $T$ of the relay for each current value, and is generally given as a curve, $T$ versus $M$, where $\mathrm{M}$ is a multiple of the pickup current, i.e. $M=\frac{I}{I p u}$, and I is the relay current (overload and/or fault). In the application reported in this paper, the overcurrent relay is conformed to the following IEC characteristic [11]:

$$
T=\frac{k_{1} T D S}{\left[M^{k_{2}}-1\right]}
$$

where: $k_{1}, k_{2}$ are constants that depend on the relay characteristic (inverse, very inverse, and extremely inverse). It is worth to mention that directional overcurrent relay allows for continuous time dial setting but discrete pickup current settings.

\subsection{Statement of the proposed formulation}

The general relay coordination problem can be stated as a parametric optimization problem. The objective function of operating times of the primary relays is optimized subject to keeping the operation of the backup relays coordinated. One possible approach to achieve minimum shock to the system due to faults would be to minimize a sum of the operating times of all primary relays hoping that the operating times of individual primary relays would be close to the minimum individual operating times that might be possible. The problem formulation can be demonstrated with the help of Fig. (1) and by assuming a network consisting of $n$ relays, the objective function $\mathrm{J}$ to be minimized can be expressed as:

$$
J=\sum_{i=1}^{n} T_{i i}
$$

where: $T_{i j}$ is the operating time of the primary relay $R_{i}$ for a close-in fault $i$,

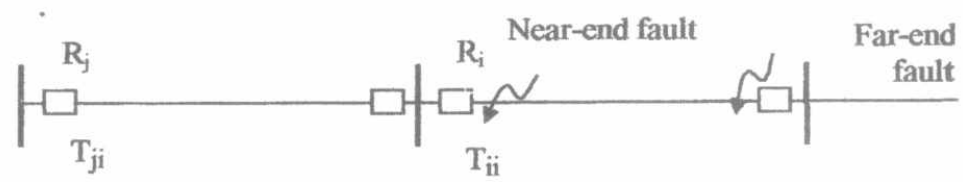

Fig. (1) An illustrative diagram for basic definitions

The operating time of the backup relay must be greater than the sum of the operating time of its primary relay and the coordination margin. This can be expressed as:

$$
T_{j i} \geq T_{i j}+\mathrm{CTI}
$$


where: $T_{j i}$ is the operating time of the backup relay $\mathrm{R}_{\mathrm{j}}$ for the same close-in fault at $i$, and $\mathrm{CTI}$ is the coordination time interval.

From equation (1) one can see that the relation between the operating time $T$ of the time overcurrent unit, and the multiple pickup current $M$, is nonlinear. Since the multiple pickup current of the relays can be predetermined, so for a fixed $\mathrm{M}$, equation (1) becomes linear as follows:

$$
T=a \cdot T D S
$$

where:

$$
a=\frac{k_{1}}{M^{k_{2}}-1}
$$

By substitution in equation (2), the objective function becomes:

$$
J=\sum_{i=1}^{n} a_{i} T D S_{i}
$$

In equation (6), ais haven't any effect on the optimal solution and can be assumed ones, they are predetermined from equation (5) and substituted in (3); values of TDS $i$ are determined by minimizing $J$ (the objective function) and satisfying the coordination between the primary and backup relays. Equation (6) is optimized using the well-known Simplex two-phase method [10] subject to the condition that the operation of the backup relays remains properly coordinated.

\section{JUSTIFICATION OF THE PROPOSED FORMULATION}

\subsection{The insignificance of weight factors consideration}

According to the mathematical formulation of the problem, it can be shown that the objective function has a negative slope and the constraints $\left(a_{\mathrm{i}} \cdot \mathrm{X}-\mathrm{b}_{\mathrm{i}} . \mathrm{Y} \geq \mathrm{c}\right)$ have positive slopes. The optimal solution will not change if the weight factors changed from a zero to infinity. The optimal solution will change only if the weight factors get negative values, but this case is unacceptable because, the weight factors are positive real numbers, and if negative values of the weight factors are accepted, some of the operating times will be maximized rather than minimized.

The following mathematical example will illustrate these facts:

$\operatorname{Min} Z=4 X_{1}+3 X_{2}$

Subject to the following constraints:

$\mathrm{X}_{1}-\mathrm{X}_{2} \quad \geq 2$

$2 \mathrm{X}_{1}-0.5 \mathrm{X}_{2} \geq 2$

Lower bounds:

$\mathrm{X}_{1} \geq 0$

$\mathrm{X}_{2} \geq 0$

By solving this problem graphically, as shown in Fig. (2), mathematically, and by simulation shown in Table (1), the following results are obtained:

$$
x_{1}=2, x_{2}=0 \text {. }
$$


Sensitivity analysis [10] means how much change is allowed in the objective coefficients. A change in the objective function coefficients can affect only the slope of the straight-line representing it. The optimum solution depends totally on the slopes of the objective function and constraints. The goal from the standpoint of sensitivity analysis is to determine the range of variation in each of the objective function coefficients that will keep a current optimum solution unchanged.

Tables $(1,2)$ give the optimal solution of the problem and the sensitivity analysis based on TORA program [10]. One can see from Table (2) that by changing the coefficients of the objective function from zero to infinity, the same optimal solution will be obtained.

It is also concluded that only one constraint of the two is active [I] (the constraint with a minimal slope) and will counteract the other constraint effect. The same thing will occur when considering the far-end fault, where the close-in fault constraints will counteract the effect of far-end fault constraint.

Table (1) Optimum solution summary

\begin{tabular}{|c|c|c|}
\hline Variable & Value & $Z$-Coefficient \\
\hline$X_{1}$ & 2 & 4 \\
\hline$X_{2}$ & 0 & 3 \\
\hline
\end{tabular}

Table (2) Sensitivity analysis of the objective coefficients due to single changes

\begin{tabular}{|c|c|c|c|}
\hline Variable & Coefficient & $\begin{array}{c}\text { MIN } \\
\text { Coefficient }\end{array}$ & $\begin{array}{c}\text { MAX } \\
\text { Coefficient }\end{array}$ \\
\hline$X_{1}$ & 4 & 0 & infinity \\
\hline$X_{2}$ & 3 & -4 & Infinity \\
\hline
\end{tabular}

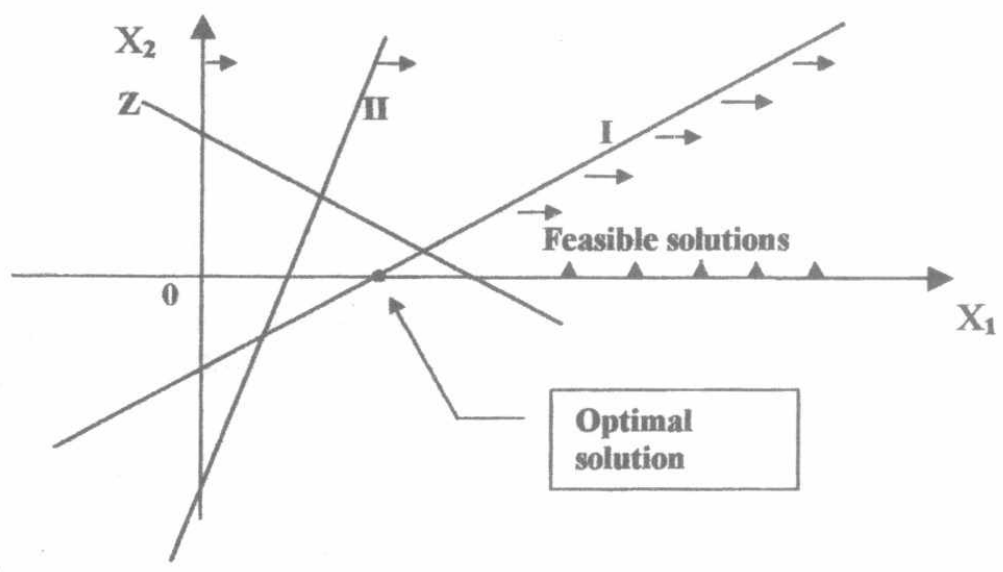

Fig. (2) Problem solution in the two dimensional domain 


\subsection{The insignificance of far-end fault consideration}

The far-end fault consideration will increase the problem dimensionality, and redundant constraints and objective function will be obtained. However, the same optimum solution will result. The authors who considered far-end fault in problem formulation, believed that the operating times of the relays for far-end fault consideration would be minimized. In fact, this consideration hasn't any advantage, because any change in the objective function coefficients such as coefficient increment hasn't any effect on the optimal solution (just as clarified in the previous section). On the other hand, the sums of operating times of the primary relays for different fault locations couldn't be considered as independent objective functions in the optimization problem formulation. The reduction of the operating times for the close-in faults will necessarily lead to the reduction of the operating times for any fault location, just as middle-line and far-end faults, but vice versa is not true. This fact is justified from the inverse overcurrent relay characteristic curves. Moreover, each relay will have two constraints $(6,8)$ but one of them is a redundant, and will be cancelled by the second one of minimum slope just as depicted in the previous mathematical example, Fig. (2). By these facts the problem dimensionality will be reduced to a half, and fast convergence will be occurred (minimum number of iterations), and consequently, fast coordination process which is more suitable for online application and the same optimal solution will be obtained.

\section{PROPOSED ALGORITHM}

Fig. (3) illustrates the flow chart of the proposed program for optimal coordination of the directional overcurrent relays. Each block of the flow chart can be briefly explained as follows:

a- Primary/Backup relay pairs (P/B): Every primary relay has its own backup. These pairs form one of the most important coordination criteria. The coordination time interval (CTI) between the primary and backup relays has been chosen to be $0.2 \mathrm{~s}$. A program for calculating the primary/backup relay pairs based on topology tracing, has been developed.

b- Load flow program: Newton-Raphson load flow technique is used in this application to determine the voltages at each bus and the line currents.

c- Fault analysis program: The fault analysis program is developed using the Thevenin's equivalent approach, to simulate a 3-phase fault for each relay location. It is worth to mention that each close-in fault can be considered as a far-end fault for far relay and vice versa.

d- Selection of pickup currents: The pickup current value of the time dependent unit can be determined according to the power system and relay design, and the experience of the protection engineer. In this paper it will be set at 1.5 times the maximum load current, for phase protection. The instantaneous unit can be set at 1.3 times the maximum far-end fault.

e- Optimal selection of TDS: The problem of overcurrent relay coordination is solved by linear programming technique, using the well known Simplex two-phase method [10] subject to the condition that the operation of the backup relays remains properly coordinated. The TDS range is taken between 0.05 to 1.1 according to equation (1). 


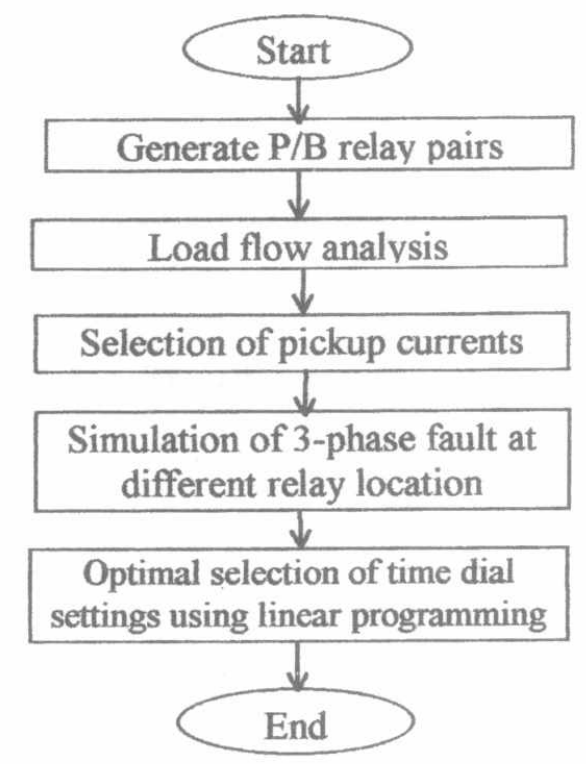

Fig. (3) Flow chart of the proposed program

\section{APPLICATION OF PROPOSED METHODOLOGY}

The developed methodology has been applied to a 3-bus test system, which is taken from Ref. [5], for a comparison purpose, and it is shown in Fig. (4), and to IEEE 14bus test system, which is shown in Fig [5]. Identical directional overcurrent relays with inverse characteristics have been used in these examples, so that $k_{1}=0.14$, $\mathrm{k}_{2}=0.02$.

\subsection{Three-bus test system example}

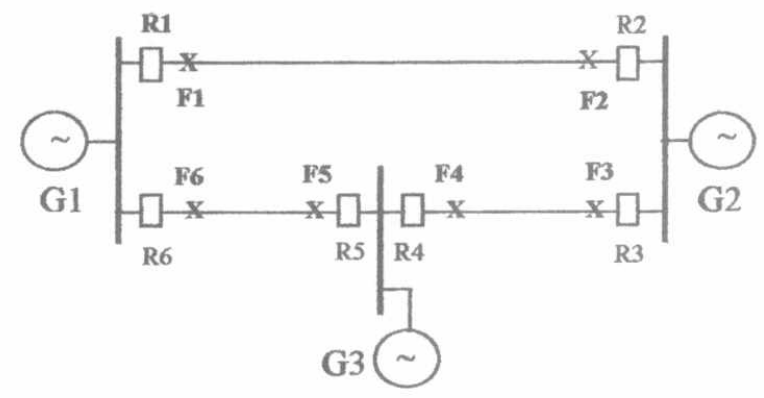

Fig. (4) Three-bus system example

The problem of determining the optimal TDS's and consequently the minimum operating times, for the close-in faults of the relays of this system can be formulated as the following linear programming problem:

Min $J=T_{11}+T_{22}+T_{33}+T_{44}+T_{55}+T_{66}$

Subject to the following constraints:

$T_{51}-T_{11} \geq 0.2$

$T_{42}-T_{22} \geq 0.2$

$T_{13}-T_{33} \geq 0.2$ 
$\mathrm{T}_{64}-\mathrm{T}_{44} \geq 0.2$

$T_{35}-T_{55} \geq 0.2$

$T_{26}-T_{66} \geq 0.2$

By substituting the values of the short circuit and pickup currents in equations $(4,5)$ then $(7,8)$, yields:

Min

[2.415*TDS1+1.7289*TDS2+2.5488*TDS3+2.5994*TDS4+1.7908*TDS5+2.092*TDS6].

Subject to:

2.8978*TDS5-2.4150*TDS $1 \geq 0.2$

4.2620*TDS4-1.7289*TDS $2 \geq 0.2$

$5.0941 *$ TDS $1-2.5488 *$ TDS $3 \geq 0.2$

4.2954*TDS6-2.5994*TDS4 $\geq 0.2$

3.9708*TDS3-1.7908*TDS $5 \geq 0.2$

$2.4935 *$ TDS2-2.0922*TDS6 $\geq 0.2$

and $\quad 1.1 \geq T D S \geq 0.1$

A linear programming technique (Simplex-two-phase method) is used as follows:

In phase I, a feasible solution is obtained and in phase II, the optimal solution is found.

The TDS and operating times of the primary and backup relays for near-end faults are shown in Table (3).

Table (3) Time dial settings and operating times of the 3 - bus test system

\begin{tabular}{|c|c|c|}
\hline \multicolumn{2}{|c|}{ No. of iteration $=7$} & Objective value $(\mathrm{min})=1.6858$ \\
\hline $\mathrm{T} 11=0.2415$ & $T 51=0.4416$ & TDS1 $=0.1000$ \\
\hline $\mathrm{T} 22=0.3115$ & $T 42=0.5114$ & TDS2 $=0.1802$ \\
\hline$T 33=0.3035$ & $\mathrm{~T} 13=0.5094$ & TDS3 $=0.1191$ \\
\hline$T 44=0.3119$ & $\mathrm{~T} 64=0.5120$ & TDS4 $=0.1200$ \\
\hline $\mathrm{T} 55=0.2729$ & T35 $=0.4729$ & TDS5 $=0.1524$ \\
\hline$T 66=0.2492$ & $T 26=0.4493$ & TDS6 $=0.1192$ \\
\hline
\end{tabular}

The authors of Ref. [5] assumed three-phase faults occurred in the middle of the transmission line to reduce the dimensionality of the problem. But, in reality, this assumption is unsuitable and results in miscoordination problem, especially when a near-end fault occur, because the coordination process must be based on the fault just beyond the primary relay, which produces maximum fault current (minimum relay's operating time) in the primary and backup relay.

The time dial settings of the relays according to Ref. [5] and without considering dynamic changes in the network topology are equal to 0.1 and consequently, the operating times of the relays for near end-faults are as shown in Table (4). The cases in which miscoordination occurred are marked with $\left({ }^{*}\right)$. 
Table (4) Operating times for near-end fault w.r.t the TDS's formulation of Ref. [5] in seconds

\begin{tabular}{|rl|rl|}
\hline \multicolumn{2}{|c|}{ Primary Relays } & \multicolumn{2}{c|}{ Backup Relays } \\
\hline T11 & 0.2415 & T51 & $0.2897^{*}$ \\
\hline T22 & 0.1728 & T42 & 0.4262 \\
\hline T33 & 0.2548 & T13 & 0.5094 \\
\hline T44 & 0.2599 & T64 & $0.4295^{*}$ \\
\hline T55 & 0.1790 & T35 & 0.3970 \\
\hline T66 & 0.2092 & T26 & $0.2493^{*}$ \\
\hline
\end{tabular}

$\left({ }^{*}\right)$ Refer to a miscoordination case

A comparison between the operating times of the relays, when a fault occurs in the middle of the line based on the presented formulation and Ref. [5] formulation is shown in Table (5). It is shown that the operating times of Ref. [5] formulation are less than the operating times of the adopted formulation. But, the proposed formulation is more suitable because it satisfies the coordination margin for near-end fault, whereas it is not in [5].

Table (5) A comparison between the results obtained from the suggested formulation and Ref. [5]

\begin{tabular}{|c|c|c|c|}
\hline $\begin{array}{l}\text { Suggested } \\
\text { approach }\end{array}$ & $\begin{array}{c}\text { Ref.[5] } \\
\text { approach }\end{array}$ & $\begin{array}{l}\text { Suggested } \\
\text { approach }\end{array}$ & $\begin{array}{l}\text { Ref.[5] } \\
\text { approach }\end{array}$ \\
\hline T11 0.3641 & 0.3641 & T51 1.3522 & 0.8873 \\
\hline T22 0.3773 & 0.2094 & T42 1.0090 & 0.8409 \\
\hline T33 0.3830 & 0.3216 & $\begin{array}{ll}\text { T13 } & 0.9633\end{array}$ & 0.9633 \\
\hline T44 0.4000 & 0.3390 & T64 0.9776 & 0.8202 \\
\hline T55 0.3534 & 0.2319 & T35 1.2697 & 1.0661 \\
\hline $\begin{array}{lll}\text { T66 } & 0.3747\end{array}$ & 0.3144 & T26 1.4131 & 0.7842 \\
\hline
\end{tabular}

Table (6) shows the sensitivity analysis of the objective function coefficients, from this table one can see that there is no effect of the weights consideration since, if the coefficients change from zero to infinity the same optimal solution will result.

Table (6) Sensitivity analysis of objective coefficients due to single changes

\begin{tabular}{|lccc|}
\hline Variable Coefficient & Min coefficient & Max coefficient \\
\hline TDS1 & 2.4150 & -2.4498 & infinity \\
\hline TDS2 & 1.7280 & -1.5520 & infinity \\
\hline TDS3 & 2.5488 & 0.0000 & infinity \\
\hline TDS4 & 2.5600 & -2.1434 & infinity \\
\hline TDS5 & 1.7900 & -1.1495 & infinity \\
\hline TDS6 & 2.0920 & -2.3212 & infinity \\
\hline
\end{tabular}




\subsection{IEEE-14 bus test system example}

The results for the IEEE 14-bus test system example are shown in Tables $(7,8)$. Table (7) depicts maximum load current which each relay sees, and choice of the CT's based on both the maximum load and fault currents, pickup settings, and the optimal TDS.

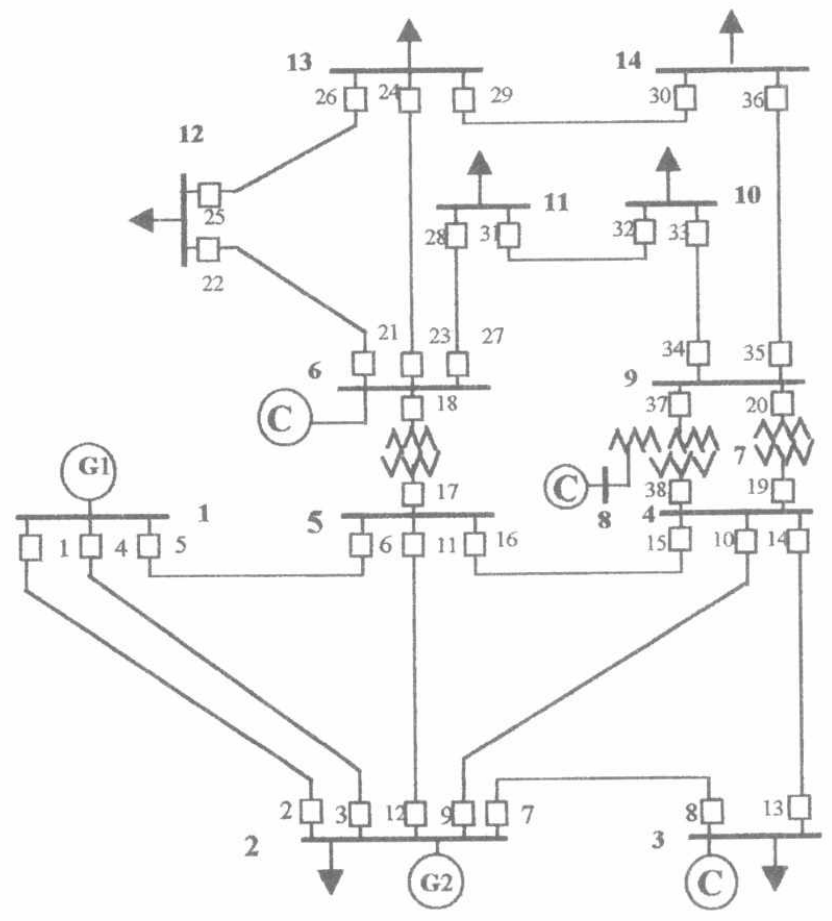

Fig. (5) IEEE 14-bus test system

The dash signal (-) in Table (7) refers that the relay which is insensitive in this direction of the current flow, in case of overload, and the directional unit will restrain the relay operation. This relay will be sensitive if the current inverses its direction, in case of fault current flow. In such a situation, the pickup current value is chosen at a minimum tap available ( 1 in this example).

\subsection{Current transformer selection}

The current transformer can be selected according to the maximum load current but it must not saturate at high fault currents. According to Ref. [12] the secondary current value of the CT must not overreach 20 times the selected CT current rating otherwise, the CT will be saturated and consequently, the protective relaying system will not operate, or operate improperly. Many researchers ignored this fact, but in this paper it is considered.

As an example consider relay 19 for which the maximum load current is $69.1 \mathrm{~A}$. Accordingly, one may directly select a CT ratio at $100 / 5$, but this selection is improper, because for a close-in 3-phase fault (3000 A), CT will be saturated and results in either no operation or improper operation of the protective device, so the CT ratio must be chosen at $200 / 5$. 
Proceedings of the $2^{\text {nd }}$ ICEENG Conference, 23-25 Nov. 1999

\begin{tabular}{|l|l|}
\hline EP-2 & 11 \\
\hline
\end{tabular}

Table (7) Optimal settings of the relays for IEEE 14-bus test system

\begin{tabular}{|ccccc||}
\hline $\begin{array}{c}\text { Relay } \\
\text { NO. }\end{array}$ & $\begin{array}{c}\text { Load } \\
\text { Current, A }\end{array}$ & $\begin{array}{c}\text { CT } \\
\text { Ratio }\end{array}$ & $\begin{array}{c}\text { Pickup } \\
\text { (1-12) }\end{array}$ & $\begin{array}{c}\text { TDS } \\
(\mathbf{0 . 0 5}-1.1)\end{array}$ \\
\hline R1 & 326.3 & $400 / 5$ & 6 & 0.0593 \\
\hline R2 & - & $200 / 5$ & 1 & 0.1732 \\
\hline R3 & - & $200 / 5$ & 1 & 0.1732 \\
\hline R4 & 326.3 & $400 / 5$ & 6 & 0.0593 \\
\hline R5 & 312.2 & $300 / 5$ & 8 & 0.0674 \\
\hline R6 & - & $200 / 5$ & 1 & 0.1427 \\
\hline R7 & 306.6 & $300 / 5$ & 8 & 0.1044 \\
\hline R8 & - & $100 / 5$ & 1 & 0.2343 \\
\hline R9 & 235.2 & $300 / 5$ & 6 & 0.1067 \\
\hline R10 & - & $200 / 5$ & 1 & 0.1900 \\
\hline R11 & - & $200 / 5$ & 1 & 0.1880 \\
\hline R12 & 173.7 & $200 / 5$ & 7 & 0.1154 \\
\hline R13 & - & $100 / 5$ & 1 & 0.4232 \\
\hline R14 & 104.4 & $200 / 5$ & 4 & 0.1497 \\
\hline R15 & - & $100 / 5$ & 1 & 0.4405 \\
\hline R16 & 272.7 & $300 / 5$ & 7 & 0.1193 \\
\hline R17 & 196.8 & $200 / 5$ & 7 & 0.1783 \\
\hline R18 & - & $200 / 5$ & 1 & 0.3881 \\
\hline R19 & 69.1 & $200 / 5$ & 2.5 & 0.2373 \\
\hline R20 & - & $300 / 5$ & 1 & 0.2623 \\
\hline R21 & 133.6 & $400 / 5$ & 2.5 & 0.3750 \\
\hline R22 & - & $100 / 5$ & 1 & 0.2843 \\
\hline R23 & 312.8 & $400 / 5$ & 6 & 0.3179 \\
\hline R24 & - & $100 / 5$ & 1 & 0.5147 \\
\hline R25 & 29.4 & $200 / 5$ & 1.2 & 0.4650 \\
\hline R26 & - & $300 / 5$ & 1 & 0.3189 \\
\hline R27 & 132.8 & $400 / 5$ & 2.5 & 0.4404 \\
\hline R28 & - & $200 / 5$ & 1 & 0.5058 \\
\hline R29 & 97.9 & $300 / 5$ & 2.5 & 0.4354 \\
\hline R30 & - & $200 / 5$ & 1 & 0.4768 \\
\hline R31 & 67.8 & $200 / 5$ & 2.5 & 0.4502 \\
\hline R32 & - & $300 / 5$ & 1 & 0.5653 \\
\hline R33 & - & $100 / 5$ & 1 & 0.5652 \\
\hline R34 & 112.3 & $300 / 5$ & 3 & 0.5117 \\
\hline R35 & 167.7 & $400 / 5$ & 3 & 0.3465 \\
\hline R36 & - & $100 / 5$ & 1 & 0.6469 \\
\hline R37 & - & $200 / 5$ & 1 & 0.3220 \\
\hline R38 & 127.2 & $200 / 5$ & 4 & 0.2149 \\
\hline & & & & \\
\hline
\end{tabular}

Table (8) shows the optimal backup/primary operating times of the relays for a closein three-phase fault at different relay locations. It is good to notice that the maximum operating time of the primary and backup relay is less than 1 and 1.2 second, respectively. 
Proceedings of the $2^{\text {nd }}$ ICEENG Conference, 23-25 Nov. 1999

\begin{tabular}{l|l|l}
\hline EP-2 & 12
\end{tabular}

Table (8) Backup/Primary operating times for IEEE 14-bus test system

\begin{tabular}{|c|c|c|c|c|c|c|}
\hline & o. $\mathrm{S}$ & Rela & no. $s$ & Rela & o. S Relay & no. $\mathrm{S}$ \\
\hline 3 & 0.4095 & 1 & 0.1900 & 18 & $0.7230 \quad 11$ & 0.3091 \\
\hline 6 & 0.3900 & 1 & 0.1900 & 5 & $0.7230 \quad 16$ & 0.5230 \\
\hline 2 & 0.4095 & 4 & 0.19 & 12 & $0.7230 \quad 16$ & 0.5230 \\
\hline 6 & 0.3900 & 4 & 0.1900 & 18 & $0.7230 \quad 16$ & 0.5230 \\
\hline 2 & 0.4095 & 5 & 0.2095 & 5 & $0.7230 \quad 17$ & 0.5224 \\
\hline 3 & 0.4095 & 5 & 0.2095 & 12 & $\begin{array}{ll}0.7230 & 17 \\
\end{array}$ & 0.5224 \\
\hline 4 & 0.5470 & 2 & 0.2661 & 15 & $0.7224 \quad 17$ & 0.5224 \\
\hline 8 & 0.5126 & 2 & 0.2661 & 22 & 1.0645 & 0.5657 \\
\hline 10 & 0.5470 & 2 & 0.2661 & 2 & $1.0645 \quad 18$ & 0.5657 \\
\hline 11 & 0.5470 & 2 & 0.2661 & 2 & $1.0110 \quad 18$ & 0.5657 \\
\hline 1 & 0.5470 & 3 & 0.2661 & & $1.0645 \quad 21$ & 0.7028 \\
\hline 8 & 0.5126 & 3 & 0.2661 & 24 & $1.0645 \quad 21$ & 0.7028 \\
\hline 10 & 0.5470 & 3 & 0.2661 & 28 & $1.0110 \quad 21$ & 0.7028 \\
\hline 11 & 0.5470 & 3 & 0.2661 & & $1.0645 \quad 27$ & 0.8645 \\
\hline 1 & 0.5470 & 7 & 0.3470 & & $1.0645 \quad 27$ & 0.8645 \\
\hline 4 & 0.5470 & 7 & 0.3470 & & $1.0645 \quad 27$ & 0.8645 \\
\hline 10 & 0.5470 & 7 & 0.3470 & & $0.9183 \quad 20$ & 0.3883 \\
\hline 11 & 0.5 & 7 & 0.3470 & & $1.1943 \quad 20$ & 0.3883 \\
\hline 4 & 0.5470 & 9 & 0.3126 & 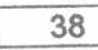 & $1.1943 \quad 20$ & .3883 \\
\hline 4 & 0.5470 & 9 & 0.3126 & & $1.1943 \quad 34$ & .9943 \\
\hline 0 & 0.512 & 9 & 0.3126 & & $1.1943 \quad 34$ & .9943 \\
\hline 11 & 0.5470 & 9 & 0.3126 & & $0.9183 \quad 35$ & .7183 \\
\hline 1 & 0.5470 & 12 & 0.3052 & & $1.1943 \quad 34$ & 0.9943 \\
\hline 4 & 0.5470 & 12 & 0.3052 & & $1.1943 \quad 35$ & 0.7183 \\
\hline 8 & 0.5126 & 12 & 0.3052 & & $1.1943 \quad 35$ & 0.7183 \\
\hline 10 & 0.5470 & 12 & 0.3052 & & $1943 \quad 37$ & 0.4878 \\
\hline 14 & 0.5722 & 8 & 0.3722 & 3 & $\begin{array}{lll}0.9183 & 37\end{array}$ & 0.4878 \\
\hline 7 & 0.8594 & 13 & 0.6594 & & $1.1943 \quad 37$ & 0.4878 \\
\hline 13 & 0.8 & 10 & 0.3148 & 34 & $1.0927 \quad 32$ & 0.8927 \\
\hline 16 & 0.7 & 10 & 0.3148 & & $1.0489 \quad 33$ & 0.8489 \\
\hline 20 & 0.8539 & 10 & 0.3148 & & $1.0318 \quad 28$ & 0.8318 \\
\hline 37 & 0.8 & 10 & 0.3148 & 21 & $1.0822 \quad 31$ & 0.8822 \\
\hline 9 & 0.8539 & 14 & 0.3683 & & $6170 \quad 22$ & 0.417 \\
\hline 16 & 0.7104 & 14 & 0.3683 & 21 & $9747 \quad 25$ & 0.7747 \\
\hline 20 & 0.8539 & 14 & 0.3683 & & $.0671 \quad 24$ & 0.7487 \\
\hline 37 & 0.8539 & 14 & 0.3683 & & $0.9487 \quad 24$ & 0.7487 \\
\hline 0 & 0.8 & 15 & 0.6539 & 2 & $1.0671 \quad 26$ & 0.4883 \\
\hline 13 & 0.8539 & 15 & 0.6539 & 30 & $0.9487 \quad 26$ & 0.488 \\
\hline 20 & 0.8539 & 15 & 0.6539 & 23 & $1.0671 \quad 29$ & 0.867 \\
\hline 37 & 0.8539 & 15 & 0.6539 & 2 & $1.0671 \quad 29$ & 0.867 \\
\hline 9 & 0.8539 & 19 & 0.4714 & 3 & $0.9613 \quad 30$ & 0.761 \\
\hline 13 & 0.8539 & 19 & 0.4714 & 29 & $1.1641 \quad 36$ & 0.9641 \\
\hline 16 & 0.7104 & 19 & 0.4714 & 15 & $0.7224 \quad 11$ & 0.3091 \\
\hline 37 & 0.8539 & 19 & 0.4714 & 5 & $0.7230 \quad 11$ & 0.309 \\
\hline 15 & 0.7224 & 6 & 0.2358 & 15 & 0.72246 & 0.235 \\
\hline 13 & 0.8539 & 38 & 0.5104 & 12 & 0.7230 & 0.235 \\
\hline 20 & 0.8539 & 38 & 0.5104 & 20 & $0.8539 \quad 38$ & 0.510 \\
\hline
\end{tabular}




\section{CONCLUSION}

This paper presented an enhanced formulation of the overcurrent relays coordination. The proposed formulation depends on a predetermination of the pickup currents of the relays and then using the linear programming for optimal operating time determination. The insignificance of weight factors and far-end fault consideration in the problem formulation are proved. For preventing a miscoordination resulting from CT's saturation at high fault currents, CT's have been chosen based on both the maximum load and fault current.

\section{REFERENCES}

[1] "Applied Protective Relaying", Westinghouse Electric Corporation, RelayInstrument Division, Coral Springs, Florida 33065, 1982.

[2] R. E. Albrecht et al. 'Digital Computer Protective Device Coordination program -1General Program Description', IEEE Trans on PAS, Vol. 83, No 4, April 1964, pp. $402-410$.

[3] M. J. Damborg, et al. 'Computer Aided Transmission Protection System Design, Part I: Algorithms', IEEE Trans on PAS, Vol. 103, No 4, 1984.

[4] L. Jenkines, H. Khincha, S. Shivakumar and P. Dash. "An Application of Functional Dependencies to the Topological Analysis of Protection Schemes", IEEE Transaction on Power Delivery, Vol. 7, No. 1, January 1992, pp. 77-83.

[5] A. J. Urdenta, et al. “ Optimal Coordination of Directional Overcurrent Relays in Interconnected Power Systems", IEEE Trans. on Power Delivery, Vol. 3, July 1988, pp. 903-911.

[6] N. A. Laway, H. O. Gupta, "A Method for Coordination of Overcurrent Relays in an interconnected Power Systems", IE Journal, Vol. 74, August 1993, pp. 59-65.

[7] B. Chattopadhyay, M. S. Sachdev and T. S. Sidhu, "An On- Line Relay Coordination Algorithm For Adaptive Protection Using Linear Programming Technique", IEEE Transactions on Power Delivery, Vol. 11, No. 1, January 1996, pp.165-173.

[8] A. J. Urdenta, L. G. Perez, and H. Resterbo, "Optimal Coordination of Directional Overcurrent Relays Considering Dynamic Changes in the Network Topology", IEEE Transaction on Power Delivery, Vol. 12, No. 4, October 1997, pp.1458-1464.

[9] A. H. Knable, Electrical Power System Engineering Problems and Solutions, McGraw Hill, New York, 1967.

[10] Hamdy A. Taha, "Operation Research An Introduction", New York, 1996.

[11] IEC Standard, Single Input Energizing Quantity Measuring Relays with Dependent Specified Time, Publication No. 255-4, 1976.

[12] IEEE PES Power System Relaying Committee, 'CT's and High Fault currents', IEEE Trans. On Power Delivery, Vol. 8, No. 3, 1993, pp. 884-897. 
